\title{
Activity of sitafloxacin against extracellular and intracellular Staphylococcus aureus in vitro and in vivo: comparison with levofloxacin and moxifloxacin
}

\author{
Gongming Shi, Xiangdong Chen, Hui Wang, Siwen Wang, Xin Guo and Xulei Zhang
}

Antibiotic activity can differ depending on whether the bacterial target is extracellular or intracellular. To determine extracellular and intracellular activities of sitafloxacin (STX) against Staphylococcus aureus in comparison with levofloxacin (LVX) and moxifloxacin (MXF) in vivo and in vitro, three S. aureus strains (ATCC25923, 29213, 43300) were evaluated. MIC, MBC and mutant prevention concentration (MPC) of the test quinolone for $S$. aureus were determined by microdilution in broth, and intracellular activity was determined in RAW264.7 cells after phagocytosis of bacteria. Cellular quinolone accumulation was determined by HPLC. The time- and concentration-kill relationships were examined in vitro (in broth and in RAW264.7 cells, respectively) and in vivo by use of a mouse peritonitis model. The results showed that the activity of STX in broth cultures, including the MIC, MBC, MPC and the time- and concentration-kill relationships, were greater for STX than those for LVX and MXF. In particular, STX exhibited the strongest activity against intramacrophage $S$. aureus. The intracellular effects could be ranked in the following order as the mean change in the $\log 10$ number of cfu ml$)^{-1}\left(\log 10 \mathrm{cfu} \mathrm{ml}^{-1}\right)$ between treated and untreated mice: STX $>$ LVX $>$ MXF. It also showed that the dominant factor of intracellular activity in vivo was the frequency of doses. There was a poor correlation between the intracellular accumulation of the three different quinolones and the actual intracellular effect. The results of the intracellular and extracellular time- and concentration-kill relationships indicated that STX has the potential to display useful activity against extracellular and intracellular $\boldsymbol{S}$. aureus.

The Journal of Antibiotics (2012) 65, 229-236; doi:10.1038/ja.2012.7; published online 15 February 2012

Keywords: a mouse peritonitis model; bactericidal effect; RAW264.7 macrophages; sitafloxacin; Staphylococcus aureus

\section{INTRODUCTION}

Staphylococcus aureus is a common pyogenic bacterium and can cause infections in both the hospital and community environments. ${ }^{1}$ In addition to the minor skin and wound infections, ${ }^{2}$ Staphylococcus aureus may also cause serious diseases, including pneumonia, ${ }^{3}$ endocarditis, ${ }^{4}$ osteomyelitis ${ }^{5}$ and meningitis. ${ }^{6}$ Therapy for $S$. aureus may often be ineffective in preventing recurrence and the ensuing mortality. ${ }^{7,8}$ This can be due to the following reasons: (1) different subcellular localization of the antibiotic and the bacteria; (2) the increased intracellular MIC due to the impaired antibacterial activity of the antibiotic, resulting from drug metabolism, altered local $\mathrm{pH}$, or protein binding; or (3) the altered bacterial responsiveness, due to changes in bacterial metabolism or growth rate. The fact that $S$. aureus survives professional and even nonprofessional mammalian phagocytes has been well described by several reports. ${ }^{9,10}$ However, the intracellular location of the bacteria might explain the slow response to antibiotic as they might be protected from the effects of antibiotics. $^{11}$

In general, intracellular antimicrobial activity is markedly impaired compared with the activity seen in broth or the extracellular milieu, ${ }^{12-14}$ although we know of situations in which the opposite is true. Antibiotic treatments should therefore be optimized not only toward the extracellular forms of $S$. aureus but also toward the intracellular forms. Some reports ${ }^{15}$ indicated that quinolone accumulated by macrophages are found in the cytosol after cell fractionation but function readily against intracellular $S$. aureus, which suggests that they can access the phagolysosomal compartment in infected cells. For this study, we selected typical representatives of antibiotics with known activities against $S$. aureus and included in commonly used guidelines for the handling of staphylococcal infections. In this context, the different quinolone, sitafloxacin (STX), levofloxacin (LVX) and moxifloxacin (MXF), were selected for the following studies. The three different quinolone exhibited strong anti-S. aureus activity in vitro, and were also expected to be useful for the clinical treatment of $S$. aureus. ${ }^{16}$ For these studies, the direct assessment of antibiotic activity in the pertinent models is warranted, and several in vitro models with either human or animal cells have been developed to study the extracellular and intracellular activities of antibiotics. ${ }^{12,14}$ Therefore, we selected and used the cell line of RAW264.7 macrophages, because they present many of the characteristics of human 
macrophages while forming a homogeneous and reproducible population. ${ }^{17}$ We used this cell line to analyze the potential relationship between the accumulation of antibiotics in cells and intracellular activity. In addition, a corresponding in vivo model has been developed to study the extracellular and intracellular activities of antibiotics. In conclusion, the present study is one of the first systematic attempts to examine the activity of STX, LVX and MXF against extracellular and intracellular $S$. aureus in vitro (in broth and cell culture) and in vivo (in a murine peritonitis model).

\section{MATERIALS AND METHODS}

Bacterial strains, antimicrobial agents and sources of other products The study used the following S. aureus strains: ATCC29213, ATCC25923, ATCC43300 (American Type Culture Collection (ATCC), Manassas, VA, USA). Drugs used were as follows: STX (BrightGene Bio-Medical Technology Co., Jiangsu, China); MXF (Bayer Schering Pharma. Co., Berlin, Germany); LVX (LuKang cisen Pharmaceutical Co., Shandong, China). The microbiological medium was obtained from NIFDC (National Institute for Food and Drug Control, Beijing, China). The cell culture medium and newborn bovine serum (NBC) were purchased from Gibco Biocult (Paisley, Scotland, UK).

\section{Cell, cell culture and assays for cell viability}

The murine macrophage cell line RAW264. $7^{18 .}$ was obtained from the ATCC, cultured in Dulbecco's modified Eagle's medium (DMEM) supplemented with $2 \mathrm{~mm}$ glutamine and $10 \% \mathrm{NBCS}$, and maintained in a $37^{\circ} \mathrm{C}$ humidified incubator containing $5 \% \mathrm{CO}_{2}$. These cells were permissive toward a large number of intracellular bacteria. Viability upon exposure to antibiotics (at the maximal concentration tested and for up to $24 \mathrm{~h}$ ) was assessed by MTT (3-(4,5)-dimethylthiahiazo(-z-y1)-3,5-di-phenytetrazoliumromide) assay, which was used essentially that method of Mosmann. ${ }^{19}$ Briefly, cells were plated in 96well plates with $100 \mu \mathrm{l}$ of cells which had previously been resuspended to $1 \times 10^{5} \mathrm{cfu} \mathrm{ml}^{-1}$. The cells were left to adhere overnight, then exposed to STX, LVX and MXF (256 $\left.\mathrm{mgl}^{-1}\right)$ in media containing 10\% NBCS, and returned to the incubator for $24 \mathrm{~h}$. Subsequently, MTT reagent $\left(5 \mathrm{gl}^{-1}\right.$ in sterile PBS) was added to the wells. Cells were returned to the incubator for $4 \mathrm{~h}$ whereupon medium was removed and DMSO was added, and OD was assessed at $490 \mathrm{~nm}$. The results were measured at the end of the experiments (more than $90 \%$ of the total cell content).

\section{In vitro susceptibility studies}

MICs were determined according to the recommendations of the Clinical and Laboratory Standard Institute (2008). MBCs were defined as the lowest concentration of each drug causing $>99 \%$ reduction in growth. MICs and MBCs were measured at $\mathrm{pH} 5.4$ and 7.4 by microdilution, with the bacterial suspension set at $1 \sim 5 \times 10^{5} \mathrm{cfu} \mathrm{ml}^{-1}$ and by using as the endpoint the drug concentration that caused a $5-\log$ decrease in the original inoculum. Mutant prevention concentration (MPC) ${ }^{20}$ was defined as the lowest drug concentration that prevented bacterial colony formation from a culture containing $>10^{10}$ bacteria. The determination was similar to that for MIC, except that $>10^{10}$ cells were tested at high drug concentrations, inoculated plates were incubated for $72 \mathrm{~h}$, and colonies were counted at $24 \mathrm{~h}$ intervals until colony numbers became constant. The MPCs were identical when exponentially growing bacterial cultures, rather than stationary-phase cells, were applied to agar plates.

\section{Cell infection and assessment of antibiotic intracellular susceptibility breakpoint}

All experiments were conducted with RAW264.7. macrophages. Bacterial cultures exhibiting logarithmic growth were centrifuged at 3000 r.p.m. for $15 \mathrm{~min}$, and the sedimented bacteria were resuspended in DMEM supplemented with $10 \% \mathrm{NBCS}$, and incubated for $30 \mathrm{~min}$ at $37^{\circ} \mathrm{C}$ to allow for opsonization. This suspension was then used to replace the culture medium of macrophages, and infection/phagocytosis was achieved by incubating macrophages with bacteria for $1 \mathrm{~h}(0.5: 1$ bacteria/macrophage ratio). Extracellular bacteria were then eliminated by washing in PBS (before the first washing, the cells were incubated for $1 \mathrm{~h}$ in DMEM supplemented by $200 \mathrm{mgl}^{-1}$ linezolid kill S. aureus). The culture medium samples were investigated for extracellular bacteria by agar plate assays. The infected macrophage samples were subjected for $24 \mathrm{~h}$ to a range of quinolone (STX, LVX and MXF) at concentrations from 0.03125 to $512 \mathrm{mg} \mathrm{l}^{-1}$. Finally, the medium was decanted, and the cell layer was quickly washed twice with PBS, cells were collected by scraping in $0.2 \mathrm{ml}$ of distilled water, and intracellular bacteria were enumerated by agar plate assays with appropriately diluted samples. In this experiment, linezolid was added at its MIC value during the whole incubation period to prevent the extracellular growth of bacteria.

\section{Determination of cellular quinolone accumulation}

Cells (infected or uninfected) were incubated with quinolone at a final concentration of $4 \mathrm{mgl}^{-1}$ for $30,180,300 \mathrm{~min}$. Then the medium was decanted, and the cell layers were quickly washed twice with PBS (this effectively removes all of the drugs not tightly cell bound, and we checked for the absence of detectable quinolone in the final wash). Cells were collected by scraping in $0.5 \mathrm{ml}$ of distilled water and sonicated $(10 \mathrm{~s}, 400 \mathrm{w})$ to achieve homogeneity. A part of each sample was withheld and used for determination of the total protein content (bicinchoninic acid method; enhanced BCA protein assay kit, Beyotime, Jiangsu, China). The remainder part was centrifuged at 18000 r.p.m. for $10 \mathrm{~min}$, and $50 \mu \mathrm{l}$ of the supernatant was used for chromatography (SHIMADZU chromatograph equipped with a UV detector (Shimadzu Co., Kyoto, Japan) (set at $295 \mathrm{~nm}$ for STX, $296 \mathrm{~nm}$ for LVX and MXF, $\left.1.0 \mathrm{ml} \mathrm{min}^{-1}\right)$ ), using a C18 column in conjunction with a precolumn, a mobile phase made of $22 \%$ acetonitrile and $78 \% 100 \mathrm{mM} \mathrm{Na}_{2} \mathrm{HPO}_{4}$ buffer ( $\mathrm{pH}$ 3.0) for STX (the limit of detection was $\sim 0.3 \mathrm{ng}, R^{2}=0.9990$ ), ${ }^{21}$ a mobile phase of $20 \%$ acetonitrile and $80 \% 20 \mathrm{mM} \mathrm{Na}_{2} \mathrm{HPO}_{4}$ buffer (pH 3.0) for LVX (the limit of detection was $\sim 0.16 \mathrm{ng}, R^{2}=0.9984$ ), ${ }^{22}$ and a mobile phase of $22 \%$ acetonitrile and $78 \% 10 \mathrm{mM} \mathrm{Na}_{2} \mathrm{HPO}_{4}$ buffer ( $\mathrm{pH}$ 2.7) for MXF (the limit of detection was $\left.\sim 0.16 \mathrm{ng}, R^{2}=0.9984\right){ }^{23}$

\section{In vitro extracellular and intracellular concentration- and time-kill studies}

For extracellular concentration- and time-kill studies, bacteria at a density of $5 \times 10^{5} \mathrm{cfu} \mathrm{ml}^{-1}$ were exposed to quinolone (STX, LVX or MXF) concentrations that varied over a wide range (0.01-fold. to 100 -fold the MPC, to obtain a full description of the pharmacological response) in broth, Incubation at $37^{\circ} \mathrm{C}$ for $24 \mathrm{~h}$ by plate assays with appropriately diluted samples. Quantification of cfu was performed with MPC after 0, 6 and $24 \mathrm{~h}$ of incubation for time-kill studies. Intracellular concentration-kill studies were performed with phagocytized bacteria, opsonized $S$. aureus was added to the cell culture medium at a 0.5:1 bacteria/macrophage ratio for $1 \mathrm{~h}$. Adherent, non-phagocytized bacteria were eliminated by washing and a short incubation $(1 \mathrm{~h})$ in Hanks buffer containing linezolid $\left(200 \mathrm{mgl}^{-1}\right)$, and thereafter, the cells were incubated with quinolones for up to $24 \mathrm{~h}$ over a wide range of extracellular concentrations (In this period, linezolid was also added at its MIC value). Then the medium was decanted, and the cell layer were quickly washed twice with PBS, cells were collected by scraping in $0.2 \mathrm{ml}$ of distilled water, and intracellular bacteria were enumerated by plate assays with appropriately diluted samples. The numbers of cellassociated cfu were measured at time zero and the end of the incubation. Quantitation of cfu was performed with MPC after 0, 6 and $24 \mathrm{~h}$ of incubation for time-kill studies.

\section{In vivo extracellular and intracellular concentration- and time-kill studies}

Mouse peritonitis model. ICR mice (weight: $25-30 \mathrm{~g}$ ) were used throughout the studies. The mice had free access to chow and water. The mice were inoculated by i.p. injection of $0.5 \mathrm{ml}$ bacterial suspension containing $5 \times 10^{6} \mathrm{cfu} \mathrm{ml}^{-1}$ and $5 \%\left(\mathrm{wt} \cdot \mathrm{vol}^{-1}\right)$ mucin. After killing the mice, peritoneal washes were performed by injecting $2 \mathrm{ml}$ of Hanks balanced salt solution i.p. and then massaging the abdomen and opening the peritoneum to collect cells and bacteria.

(1) Determination of maximum drug concentration in serum (Cmax): Uninfected serum samples were obtained at intervals from mice injected 
s.c. with the test drugs at $100 \mathrm{mg} \mathrm{kg}^{-1}$. Drug concentrations were determined from the diameter of zones of growth inhibition around disks saturated with sample solutions, which were placed onto agar plates inoculated with Bacillus subtilis as an indicator bacterium. ${ }^{24}$

(2) Extracellular and intracellular dose-kill studies: Mice were treated s.c. with five different single doses of STX, LVX or MXF (200, $100,50,20,10 \mathrm{mg} \mathrm{kg}^{-1}$; four mice per group) $2 \mathrm{~h}$ after inoculation, and samples were obtained after $4 \mathrm{~h}$ of drugs exposure. Untreated control groups were included.

(3) Extracellular and intracellular time-kill studies: Mice were treated with one or three doses of STX, LVX or MXF $\left(100 \mathrm{mg} \cdot \mathrm{kg}^{-1}\right)$ and received the first dose $2 \mathrm{~h}$ after inoculation (four mice per group). The three-dose regimen was administered every $8 \mathrm{~h}$. The mice were sampled $19 \mathrm{~h}$ after treatment onset. Untreated control groups were included, but only for $6 \mathrm{~h}$ time point post infection. At this point, untreated mice met the clinical signs of irreversible bacteremia and were euthanized.

(4) Separation of extracellular and intracellular S. aureus in the peritoneal wash: The peritoneal fluid was collected from each mouse. The total amount of bacteria was quantified before any other procedure was performed. A volume of $0.6 \mathrm{ml}$ of the pooled samples was transferred to tubes and the tubes were centrifuged at 300 r.p.m. and $25^{\circ} \mathrm{C}$ for $5 \mathrm{~min}$. The extracellular bacteria were still suspended, while the cells were sedimented. The extracellular bacteria in the supernatant were quantified. Then, the samples were centrifuged at 3000 r.p.m. and $25^{\circ} \mathrm{C}$ for $10 \mathrm{~min}$, and the sedimentated cells were resuspended in Hanks balanced salt solution with $200 \mathrm{mgl}^{-1}$ of linezolid. The suspension was incubated $37^{\circ} \mathrm{C}$ for $1 \mathrm{~h}$ to kill the remaining extracellular bacteria. A cell-free bacterial suspension was run in parallel as a control for extracellular killing. The linezolid was then removed by washing the samples twice with $2.0 \mathrm{ml}$ Hanks balanced salt solution. The samples were finally resuspended in $1.5 \mathrm{ml}$ of sterile water for cell lysis, and the intracellular bacterial count was quantified.

\section{Curve fitting and statistical analyses}

Curve fitting was performed using a sigmoidal dose-response equation (Graph Pad Prism version 5.01, Graph Pad Software, San Diego, CA, USA) to obtain, for each condition, numeric values of two key descriptors: (i) the decrease in the number of cfu for an infinitely large concentration of antibiotic (relative maximal efficacy (Emax; in $\log _{10}$ cfu units)); (ii) the concentration of antibiotic resulting in no apparent bacterial growth compared with the original inoculum (static concentration (Cs; in $\mathrm{mgl}^{-1}$ or multiples of MPC)). Statistical analyses were performed using Graph Pad Instat version 3.06 (Graph Pad Software).

\section{RESULTS}

In vitro extracellular and intracellular susceptibility of quinolone In the test of in vitro antimicrobial activities, the MICs of the three different quinolones against clinical isolates of $S$. aureus are shown in Table 1. The order was STX $\left(0.015-0.031 \mathrm{mgl}^{-1}\right)>\mathrm{MXF}$ $\left(0.031-0.063 \mathrm{mg}^{-1}\right)>\operatorname{LVX}\left(0.25-0.5 \mathrm{mg} \mathrm{l}^{-1}\right)$. For the anti-S. aureus ATCC25923, 29213, 43300 activities of the quinolone in broth, the following results were obtained as shown in Table 2. First, the MIC was ranked in the order of STX $\left(0.015-0.031 \mathrm{mgl}^{-1}\right)>\operatorname{MXF}(0.031-$ $\left.0.063 \mathrm{mgl}^{-1}\right)>\operatorname{LVX}\left(0.25-0.5 \mathrm{mgl}^{-1}\right)$. Second, the order of MBC was STX, MXF $\left(0.063-0.25 \mathrm{mgl}^{-1}\right)>\operatorname{LVX}\left(1-4 \mathrm{mg} \mathrm{l}^{-1}\right)$. Third, for MPC, the order was STX $\left(0.031-0.125 \mathrm{mgl}^{-1}\right)>\operatorname{MXF}\left(0.125-1 \mathrm{mgl}^{-1}\right)>$ LVX (0.5-8 $\left.\mathrm{mg} \mathrm{l}^{-1}\right)$. Overall, based on these antimicrobial parameters, the in vitro activities of STX was somewhat greater than that of MXF and was much greater than that of LVX. In cell culture medium (DMEM), anti-S. aureus activities of the quinolone were similar compared with that in broth.

Furthermore, an attempt to approach what could be defined as an intracellular susceptibility breakpoint, was used to correlate the level of intracellular activity with the MIC. However, the maximal relative
Table 1 STX, LVX and MXF activity with clinical isolates of $S$. aureus

\begin{tabular}{lllllllll}
\hline & \multicolumn{2}{c}{ Sitafloxacin } & & \multicolumn{2}{c}{ Levofloxacin } & & \multicolumn{2}{c}{ Moxifloxacin } \\
\cline { 2 - 3 } S. aureus strain & MSSA & MRSA & & MSSA & MRSA & & MSSA & MRSA \\
\hline MIC $_{50}\left(\mathrm{mgl}^{-1}\right)^{\mathrm{a}}$ & 0.063 & 0.5 & & 1 & 8 & & 0.25 & 4 \\
$\mathrm{MIC}_{90}\left(\mathrm{mgl}^{-1}\right)^{\mathrm{b}}$ & 1 & 2 & & 4 & 16 & & 4 & 32 \\
\hline
\end{tabular}

Abbreviations: LVX, levofloxacin; MXF, moxifloxacin; STX, sitafloxacin.

${ }^{a} \mathrm{MIC}_{50}$ drug concentration at which $50 \%$ of isolates are inhibited.

${ }^{\mathrm{b}} \mathrm{MIC}_{90}$ drug concentration at which $90 \%$ of isolates are inhibited.

intracellular activity of the three different quinolone is considerably less active than its extracellular activity (as measured in broth). The following results were obtained as shown in Table 3 and the order of minimum bactericidal concentration was STX (32-64 $\left.\mathrm{mgl}^{-1}\right)>\mathrm{MXF}$, LVX $\left(>512 \mathrm{mgl}^{-1}\right)$. In preliminary conclusion, the extra- and intracellular activities of STX were better than that of LVX and MXF.

\section{Validation of the intracellular model}

The model needed one antibiotic in the medium to prevent the extracellular growth of the bacteria released from macrophages 6 to $8 \mathrm{~h}$ after phagocytosis. On the basis of some reports, ${ }^{25}$ linezolid was added to the culture medium to prevent this contamination. We found that a linezolid concentration as low as $0.01 \times$ its $\operatorname{MIC}\left(0.5,1\right.$ and $0.25 \mathrm{mg} \mathrm{l}^{-1}$ for S. aureus ATCC25923, ATCC29213 and ATCC43300, respectively) reduced the extracellular contamination to a negligible level, although it still allowed a marked increase in the number of cell-associated cfu. A further increase in the extracellular concentration of linezolid to its MIC allowed extracellular contamination to go to undetectable levels. Because of all those uncertainties in the true level of intracellular growth of $S$. aureus and the potential impact of even low concentrations of linezolid, intracellular activities were therefore expressed as the difference from the controls which meant that use of linezolid could be allowed in the controls. The model is nevertheless suitable if activity is defined as a reduction in cfu in comparison with the original inoculum.

\section{Cellular accumulation of quinolone}

Figure 1 shows the time profiles of the accumulation of STX, MXF and LVX by uninfected and infected cells over a $5 \mathrm{~h}$ period. The accumulation was maximal after only $30 \mathrm{~min}$ of incubation and remained almost constant thereafter. Marked differences were observed among drugs, with the following ranking: MXF $>$ STX $>$ LVX. Differences between uninfected and infected cells were small and not significant.

In vitro extracellular and intracellular concentration- and time-kill studies

In a series of experiments, time-kill curves were performed with STX, LVX and MXF for the three different $S$. aureus in broth and after phagocytosis by mouse RAW264.7 macrophages, using a fixed concentration of each antibiotic corresponding to its MPC (total drug). The results are presented in Figure 2. In broth, STX was characterized by a very great bactericidal effect, reaching a $6 \log _{10}$ units decrease in about $24 \mathrm{~h}$, followed by LVX and MXF. When the intracellular activity is considered, all antibiotics showed a marked decrease in the rate of their antibacterial effect. Less than a $1 \log _{10}$ unit decrease in the bacterial counts was observed at concentrations above the extracellular MPC after $24 \mathrm{~h}$. As a result, the STX bactericidal effect was greater than that of MXF and LVX (less than a $1 \log _{10}$ unit decrease, or no progression overtime after $24 \mathrm{~h}$ ) against S. aureus ATCC25923, 29213, but LVX effect was better than STX and MXF against $S$. aureus 
Table 2 MIC, MBC and MPC of test quinolones for S. aureus in broth at pH 7.4

\begin{tabular}{|c|c|c|c|c|c|c|c|c|c|c|c|}
\hline \multirow{2}{*}{$\begin{array}{l}\text { Strain no. } \\
\text { Concentration }\left(\mathrm{mgl}^{-1}\right)\end{array}$} & \multicolumn{3}{|c|}{ ATCC25923 } & \multicolumn{3}{|c|}{ ATCC29213 } & \multicolumn{3}{|c|}{ ATCC43300 } & \multirow[b]{2}{*}{$C \max ^{\mathrm{a}}$} & \multirow[b]{2}{*}{ Dosage and route } \\
\hline & MIC & $M B C$ & $M P C$ & MIC & $M B C$ & $M P C$ & MIC & $M B C$ & MPC & & \\
\hline Levofloxacin & 0.5 & 1 & 0.4 & 0.25 & 4 & 4 & 0.5 & 1 & 8 & 4 & 400 mg p.o. \\
\hline Moxifloxacin & 0.063 & 0.125 & 0.125 & 0.063 & 0.063 & 1 & 0.031 & 0.25 & 0.125 & 4 & 400 mg p.o. \\
\hline
\end{tabular}

Abbreviation: MPC, mutant prevention concentration.

${ }^{a}$ Concentrations corresponding to the peak concentrations of the respective antibiotics in serum after administration of currently used and/or approved doses for humans, as indicated in Keating, ${ }^{16}$ Barcia-Macay et al. ${ }^{25}$ and Zhao and Drlica. ${ }^{26}$

b.o., oral.

Table 3 The MBC of test quinolones against intracellular $S$. aureus

\begin{tabular}{lccc}
\hline Strain no. & ATCC25923 & ATCC29213 & ATCC43300 \\
\hline Sitafloxacin $\left(\mathrm{mgl}^{-1}\right)$ & 32 & 32 & 64 \\
Levofloxacin $\left(\mathrm{mgl}^{-1}\right)$ & $>256$ & $>256$ & $>256$ \\
Moxifloxacin $\left(\mathrm{mgl}^{-1}\right)$ & $>256$ & $>256$ & $>256$ \\
\hline
\end{tabular}

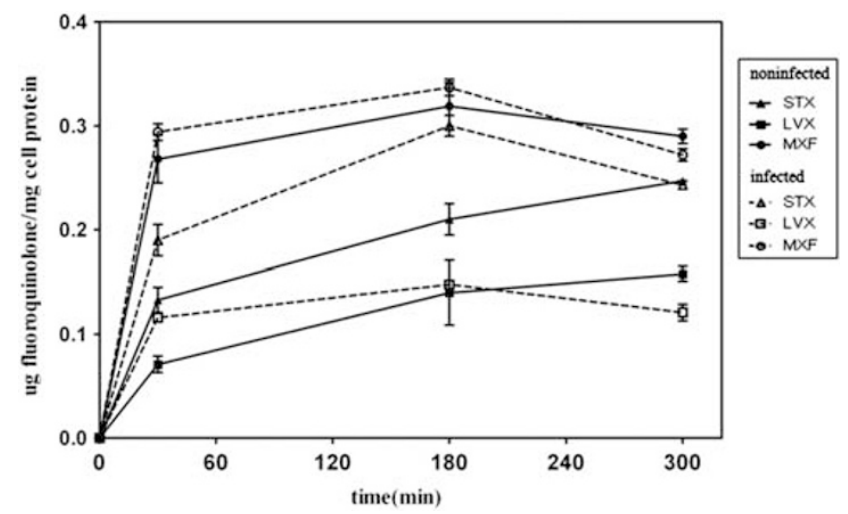

Figure 1 Cellular accumulation of quinolones upon incubation of uninfected (closed symbols and continuous lines) and infected (infected S. aureus ATCC25923, open symbols and broken lines) RAW264.7 macrophages exposed to STX (triangles), LVX (squares) or MXF (circles) at a fixed extracellular concentration $\left(4 \mathrm{mg} \cdot \mathrm{I}^{-1}\right)$ for the time periods indicated. Each value is the mean of three independent experiments (mean \pm s.e.m.; $n=3$ ).

ATCC43300. In a second series of experiments, Figure 3 and Table 4 show the extra- and intracellular concentrations and response of STX, LVX and MXF against the three different $S$. aureus in broth and in RAW264.7 macrophages, when tested over a wide range of concentrations (0.01-fold to 100 -fold the MPC) for $24 \mathrm{~h}$. The maximal relative efficacy (Emax) of all compounds was considerably reduced intracellularly when compared with the extracellular values. All drugs displayed similar relative potencies against extracellular bacteria; their relative efficacies (Emax) decreased by $\sim 7 \log _{10} \mathrm{cfu} \mathrm{ml}{ }^{-1}$, close to the limit of detection. Against intracellular bacteria, all drugs had significant decreases in their relative efficacies (Emax), but these decreases were roughly similar (Emax against intracellular bacteria/ Emax against extracellular bacteria ratios, 0.109 (minimum) to 0.499 (maximum)). As for bacteria phagocytized by RAW264.7 macrophages, STX was the most active agent against $S$. aureus when considering its Emax, followed by LVX and MXF. The static concentration (Cs) of STX was considerably lower than that of LVX and MXF. In the cell culture model, the extracellular kill curves were measured in broth without cells, which offers optimal growth conditions for the bacteria.

\section{Determination of Cmax}

Results showed the pharmacokinetics of STX, LVX and MXF given to mice s.c. at $100 \mathrm{mg} \mathrm{kg}^{-1}$. Cmax values of the quinolone in mouse blood were determined as follows: STX, $11.18 \mathrm{mgl}^{-1}$; LVX, $11.58 \mathrm{mgl}^{-1}$; and MXF, $15.63 \mathrm{mgl}^{-1}$. Cmax values of MXF were significantly greater than those of STX and LVX. Using these pharmacokinetic parameters, next the time-kill study of quinolone against intracellular S. aureus residing within mouse peritoneal macrophages were examined when the quinolone were added at the Cmax.

\section{In vivo effect of one dose and three doses on extracellular and} intracellular $S$. aureus

Time-kill curves displaying the changes cfu in the peritoneums of mice over time after treated with quinolone in relation to the number of doses given are shown in Figure 4. LVX and MXF did not show an effect by the number of doses on the total, extracellular, or intracellular colony counts. In contrast, the infection outcome was highly affected by the number of doses given in the mice treated with STX.

In total, a decrease in the colony counts of approximately $2-3 \log _{10}$ units during the $19 \mathrm{~h}$ of treatment was estimated for the mice receiving one and three doses of LVX and MXF, but mice receiving three doses of STX estimated a decrease in the colony counts of approximately $4 \log _{10}$ units. In extracellular conditions, a reduction of approximately $2 \log _{10}$ units appeared with in the first $4 \mathrm{~h}$ of treatment for mice treated with LVX and MXF, and a reduction of $1 \log _{10}$ unit occurred for the following $15 \mathrm{~h}$. But a reduction of $3 \log _{10}$ units appeared for mice receiving one dose of STX during the $4 \mathrm{~h}$ of treatment, and a reduction of more than $5 \log _{10}$ units occurred for the mice receiving three dose. In intracellular conditions, a reduction of approximately $2 \log _{10}$ units appeared with in the first $4 \mathrm{~h}$ of treatment for mice treated with LVX and MXF, and no regrowth appeared for the following $15 \mathrm{~h}$, irrespective of the number of doses. Whereas for mice receiving one dose of STX a reduction of $5 \log _{10}$ units appeared during the $4 \mathrm{~h}$ of treatment, an increase in the colony count of more than $2.5 \log _{10}$ units was observed compared with the bacterial level at the start of treatment for the subsequent $15 \mathrm{~h}$. However, a reduction of more than $5 \log _{10}$ units occurred for the mice receiving three doses of STX.

In vivo extracellular and intracellular dose-response relationships Figure 5 shows the full pharmacological response of extracellular and intracellular isolates of strains to quinolone at $4 \mathrm{~h}$ when they were exposed to a wide range of extracellular concentrations $(10,20,50$, $\left.100,200 \mathrm{mg} \mathrm{kg}^{-1}\right)$. Significant dose-response correlations were recorded both for the total count and when the counts were separated 


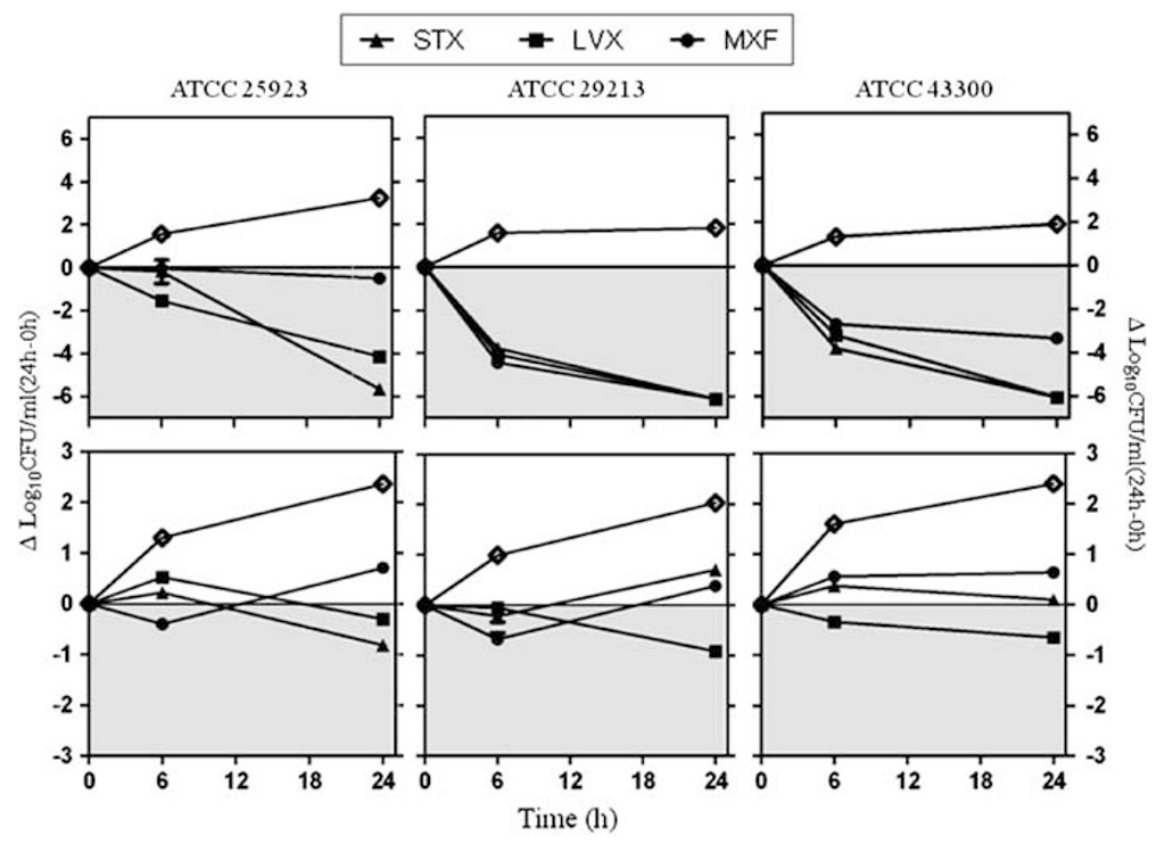

Figure 2 In vitro time-kill curves of STX, LVX and MXF corresponding to its MPC (total drug) against three different S. aureus. Activity against the extracellular form of the bacteria measured in broth (upper panels), activity against the intracellular form of the bacteria measured in RAW264.7 macrophages (lower panels). The gray shades display decreased colony counts compared with the starting bacterial count, and the white shades display increased colony counts compared with the starting bacterial count. The graphs showed the activity as changes in the numbers of cfu ( $\Delta$ logcfu, means \pm s.d.; $n=3$ ). Cells incubated with MIC of linezolid served as controls for all subsequent experiments.

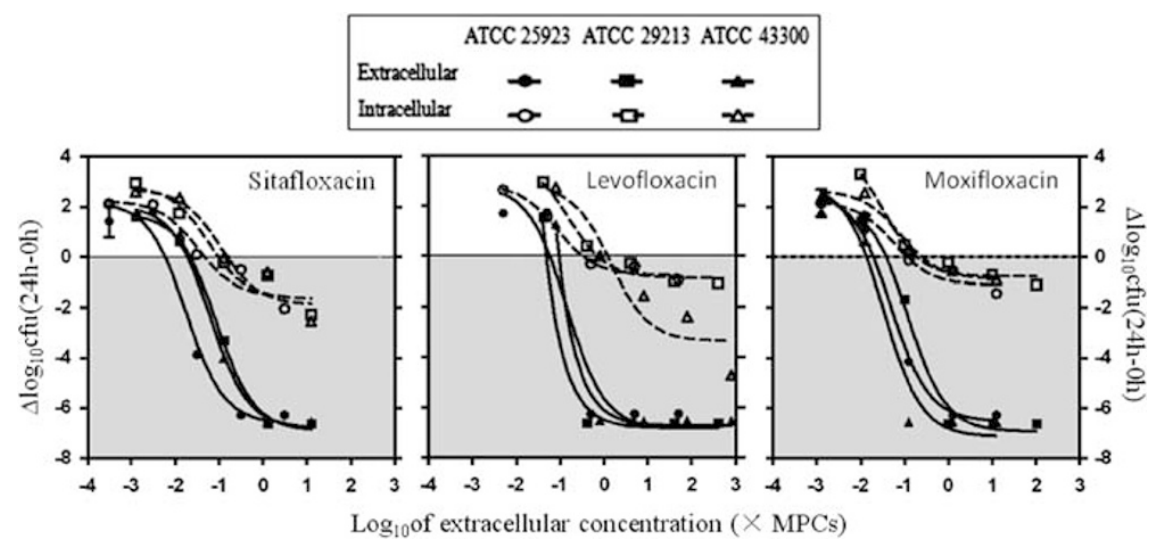

Figure 3 Concentration-response curves of three different extracellular (in broth) and intracellular (in RAW264.7 macrophages) s. aureus exposed to STX, LVX and MXF for $24 \mathrm{~h}$. The ordinate showed the change in the number of cfu ( $\Delta \operatorname{logcfu}$, means \pm s.d.; $n=3$ ) per ml of culture medium (extracellular, filled symbols; intracellular, open symbols) compared with the initial inoculum (broken line at 0). The abscissa showed the antibiotic concentration (total drug) expressed as multiples of the extracellular MPC of each antibiotic for the corresponding strain. The gray shades display decreased colony counts compared with the starting bacterial count, and the white were as display increased colony counts compared with the starting bacterial count. The data were used to fit sigmoidal functions (Hill's equation; slope factor=1). The goodness of fit $\left(R^{2}\right)$ and key pharmacodynamic parameters derived from each function $\left(\mathrm{E}_{\mathrm{max}}\right.$ and $\mathrm{C}_{\mathrm{s}}$ ) for each condition are shown in Table $4 .^{29}$

into the extra- and intracellular compartments. In total, a reduction of probably $1 \log _{10}$ unit appeared within $4 \mathrm{~h}$ of treatment for mice treated with LVX and MXF, and a reduction of approximately $2.5 \log _{10}$ units occurred for mice treated with STX. In the extracellular compartment, a decrease in the colony counts of approximately $1-2 \log _{10}$ units during the $4 \mathrm{~h}$ of treatment with LVX and MXF, and a reduction of probably $3 \log _{10}$ units occurred for mice treated with STX. In intracellular, an increase of probably $1 \log _{10}$ unit appeared for mice treated with LVX and MXF. Nevertheless, STX showed a Emax of a $0.5 \log _{10}$ unit decrease, despite the impairment of its intracellular antibiotic activity.

\section{DISCUSSION}

In the present study, based on MIC, MBC and MPC, the in vitro activities of STX were regarded as somewhat greater than that of MXF and much greater than that of LVX. STX showed maximal extracellular activity as long as its MPC for the three different $S$. aureus (ATCC25923, 29213, 43300) did not exceed $0.5 \mathrm{mgl}^{-1}$. Because no resistant colonies were recovered even when $>10^{10}$ cells were plated, and resistant mutants were selected exclusively within a concentration range (mutant selection window) ${ }^{26}$ that extended from the point where growth inhibition begins, approximated by the MIC, up to the 
Table 4 Pertinent regression parameters (with $95 \% \mathrm{Cl}$ ) and statistical analysis of the concentration-response curves illustrated in Figure

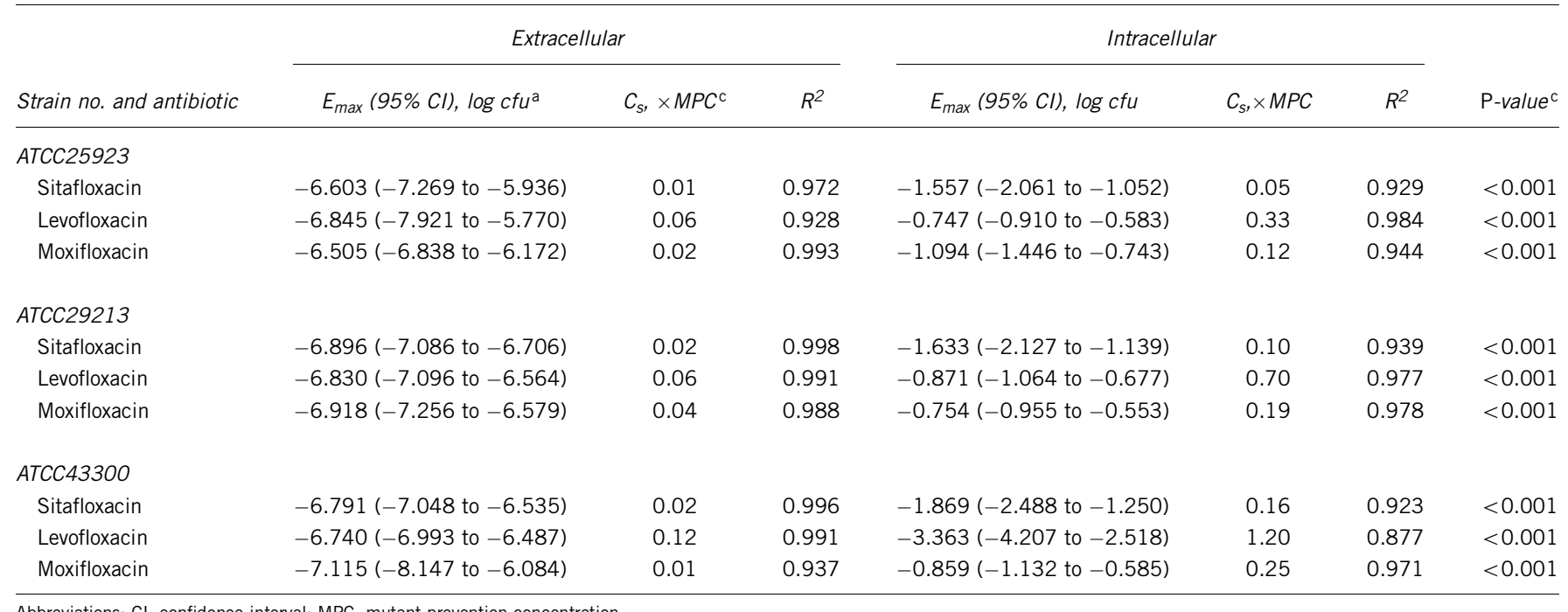

Abbreviations: $\mathrm{Cl}$, confidence interval; MPC, mutant prevention concentration.

${ }^{a} E_{\max }$, Maximal relative efficacy, decreased in logcfu after $24 \mathrm{~h}$ compared with original inoculum $(t=0 \mathrm{~h})$ and extrapolated for an infinitely large antibiotic concentration. ${ }^{a} E_{\max }$, Maximal relative efficacy, decreased in logcfu after $24 \mathrm{~h}$ compared with original inoculum $(t=0 \mathrm{~h}$ ) and extrapolated for an infinitely large antibiotic concentration.
${ }^{\mathrm{b}} \mathrm{Cs}$, Static concentration, concentration (in $\times \mathrm{MPC}$ ) resulting in no apparent bacterial growth at $24 \mathrm{~h}$ compared with the initial inoculum ( $t=0 \mathrm{~h}$ ), as determined by graphical interpolation using the

${ }^{c} P$-values determined by analysis of covariance for extracellular versus intracellular concentrations between all drugs.

\begin{tabular}{|c|c|c|}
\hline \multicolumn{3}{|c|}{ ATCC 25923} \\
\hline \# STX 1dose & \# LVX 1dose & - MXF 1dose \\
\hline$-\nabla \cdot$ STX 3dose & a. LVX 3dose & $\rightarrow$ MXF 3dose \\
\hline
\end{tabular}

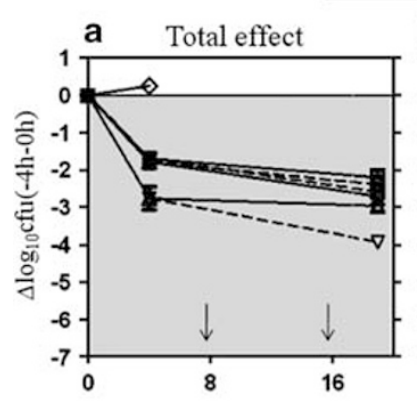

b Extracellular effect

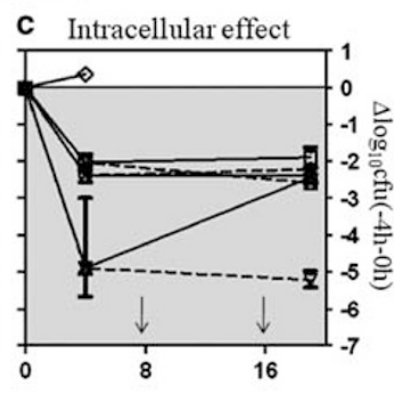

Figure 4 In vivo time-kill curves showing the change in the numbers of $\mathrm{cfu}$ in the peritoneums of mice ( $\Delta$ logcfu, mean \pm range; $n=4$ ) compared with the number of doses of STX, LVX and MXF (100 $\mathrm{mg} \mathrm{kg}^{-1}$ ). (a) Change in the total count; (b) change in extracellular count; (c) change in intracellular count. The ordinate showed the change in the number of cfu. The arrows at the abscissa indicated the times of dosing the second and third doses of drugs. The gray shades display decreased colony counts compared with the starting bacterial count, and the white shades display increased colony counts compared with the starting bacterial count.

MPC. Therefore, MPC was used to the concentration- and time-kill studies.

In the in vitro studies, the model was suitable as a tool for the first screening of intracellular activity and had the advantage of being able to study a specific constellation of drug and cell types. Our results showed that the intracellular activity of new antibiotics should be addressed early on during the selection and development process, whereas the in vivo model should also be used when extended knowledge of drug efficacy and PK/PD relationships are needed. The two models therefore complemented each other very well and might be used to obtain important knowledge of the extra- and intracellular activities of both potentially new antibiotics and wellestablished antibiotics such as STX.

In this cell culture model, the RAW264.7 cells displayed poor intrinsic defenses against intracellular infection. The antibiotic concentration and the number of cells remained fairly constant, which allowed exploration of the effect of antibiotics over a wide range of known concentrations. This model therefore offered valuable information concerning the specific extra- and intracellular activities of the drug by excluding other parameters that could affect the antimicrobial activity. Our work demonstrated that the maximal relative intracellular activity (Emax) of quinolone is considerably lower than its extracellular activity (measured in broth). First, all quinolone studied here, show concentration-dependent effects (for the three molecules tested in detail, we even observed typical pharmacological dose-response curves with the classical basic properties of threshold, slope, and maximal effects upon increasing concentration, irrespective of their specific modes of action; see Figure 3, Table 4). This definitely helps to provide an understanding of why contradictory results are reported when only narrow ranges 


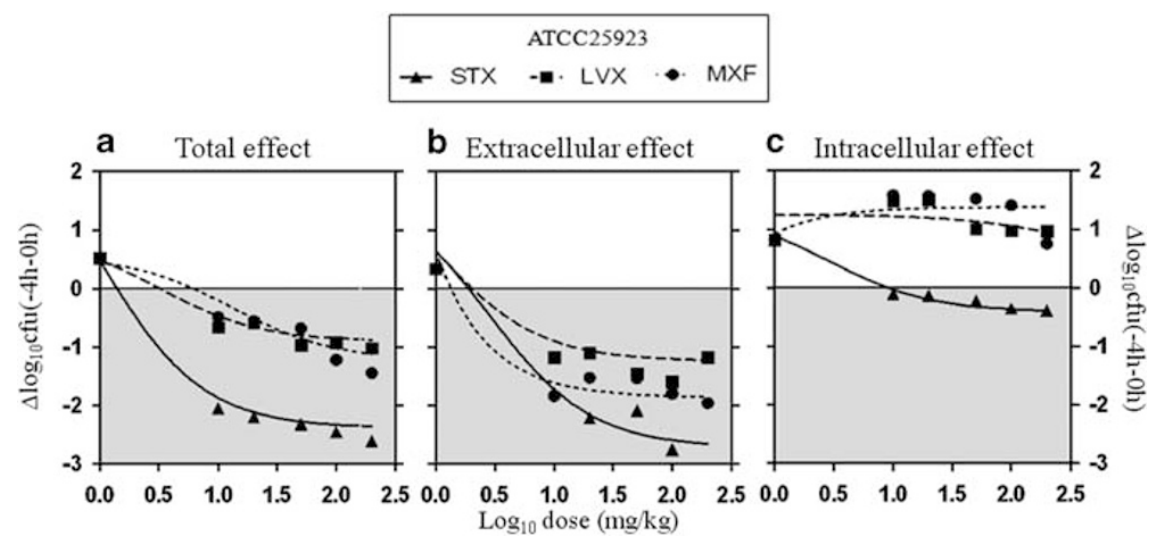

Figure 5 Dose-response curves for STX, LVX and MXF showing the change in the numbers of $\log _{10}$ cfu in the peritoneal wash in mice after $4 \mathrm{~h}$ of treatment in relation to dose. (a) Change in the total count; (b) change in extracellular count; (c) change in intracellular count. The ordinate showed the change in the number of cfu $(\Delta \log c f u$, means; $n=4)$. The dark gray were as display decreases in colony counts compared with the starting level of bacteria, and the light gray were as display increases in colony counts compared with the starting level of bacteria.

of extracellular concentrations are explored. But all drugs did not show time-dependent effects when they were tested at MPC (Figure 2). These studies suggested that the activities of three different quinolone were related with their concentrations. However, despite a higher intrinsic activity and a higher level of accumulation, intracellular activities of LVX and MXF against $S$. aureus were not better than STX in vitro.

Although the in vitro model could help in rationalizing the treatment of staphylococcal infections, the clinical significance of the present data remains conjectural, mainly because the in vitro model used here suffers from several limitations that have been discussed elsewhere. ${ }^{17,27-29}$ However, the in vitro models could not easily simulate drug pharmacokinetics/pharmacodynamics as they exist in animals and could not evaluate the interaction between a fully functional immune system and antibiotic treatment.

Nevertheless, the in vivo model had the advantage of allowing the study conducted in a whole-body system, for example, it included a fully functional immune system, so whole-body drug kinetics were occurring, and the intracellular infection was dynamic. Both the in vivo and the in vitro models used to assess intracellular antibacterial effect had their own advantages, disadvantages, and limitations. Therefore, it was necessary that both the pharmacodynamic evaluation of the extra- and intracellular activities of STX, LVX and MXF against S. aureus were carried out in vivo.

For in vivo studies, some methodological pitfall should be considered. (i) Loss of bacteria happened along with the in vivo separation assay. The sum of extra- and intracellular bacterial counts were always smaller than before the operation. To isolate the cells and the intracellular bacteria from the extracellular bacteria, the cell suspension required centrifugation. Cell lysis might also occur during the separation assay, which could confuse the separation of extra- and intracellular bacteria. However, cell lysis could be restrained by careful sample handling during the whole separation assay. Because of the above reasons, the comparison can be conducted among the samples that had undergone the same isolation procedure. Besides, the counts should be evaluated separately, whether the total, extracellular, or intracellular bacterial counts. (ii) After $2 \mathrm{~h}$ of infection, the variation of intracellular bacterial counts was more significant than the total and extracellular counts. This indicated that the number of intracellular bacteria was not static. and the significant variation was due to both the potential intracellular bacterial growth and internalized extracellular bacteria because of phagocytosis. As the phagocytosis and cell lysis continue throughout the whole infectious process, the dynamic nature of intracellular bacterial counts should be considered. Besides, the migration of new cells to the infection site occurred in the whole process.

Compared with the usual clinical dose $\left(10 \mathrm{mg} \mathrm{kg}^{-1}\right.$ per adult $)$, the test quinolone applied to mice in the present study was far higher $\left(100 \mathrm{mg} \mathrm{kg}^{-1}\right)$. Therefore, animal experiments are absolutely necessary to make a precise comparison of the therapeutic activities of the three quinolone. The results of the dose-response study with STX, LVX and MXF (Figure 5) give insight to the dose-response relationship in extra- and intracellular study. The curves show that the dose needed in intracellular compartment is higher than in extracellular compartment to obtain the same effect.

The results for STX (Figure 4) showed that the difference in dose can affect the intracellular activity-time profile of an antibiotic. The difference in effects on the animals that received a single dose could be accounted by whether the colony counts were obtained after 4 or $21 \mathrm{~h}$. On the basis of the results alone, we concluded that STX was superior to LVX and MXF intracellularly after the administration of one and three doses. Therefore, in intracellular activity studies, the timing of treatment onset should be carefully designed. However, the extra-and intracellular activity of STX against $S$. aureus was greater than LVX and MXF in vivo.

In conclusion, STX showed a higher relative antibiotic potency than LVX and MXF (lower values for the Emax and Cs pharmacodynamic parameters). Meanwhile, when used at the same weight concentration, the intracellular antimicrobial activity of STX was obviously superior over LVX and MXF. STX displayed significant activity against S. aureus isolates and could be very useful where not only eradication of extracellular forms is required, but also significant reduction of the intracellular bacteria is desirable. In the circumstances that intracellular component is required to combat infections, STX can be very useful.

\section{ACKNOWLEDGEMENTS}

This work was supported by the Department of Microbiology. We thank $\mathrm{Z}$ Shun, S Zhang and XH Yang for their dedicated technical assistance during the in vitro and in vivo studies. 
1 Kuehnert, M. J. et al. Methicillin-resistant-Staphylococcusaureus hospitalizations, United States. Emerg. Infect. Dis. 11, 868-872 (2005).

2 Iyer, S. \& Jones, D. H. Community-acquired methicillin-resistant Staphylococcusaureus skin infection: a retrospective analysis of clinical presentation and treatment of a local outbreak. J. Am. Acad. Dermatol. 50, 854-858 (2004).

3 Ferrara, A. M. Treatment of hospital-acquired pneumonia caused by methicillinresistant Staphylococcusaureus. Int. J. Antimicrob. Agents 30, 19-24 (2007).

4 Fowler, V. G. Jr. et al. Staphylococcusaureus endocarditis: a consequence of medical progress. JAMA 293, 3012-3021 (2005).

5 Jensen, A. G., Espersen, F., Skinhoj, P. \& Frimodt-Moller, N. Bacteremic Staphylococcusaureus spondylitis. Arch. Intern. Med. 158, 509-517 (1998).

6 Pedersen, M., Beneld, T. L., Skinhoej, P. \& Jensen, A. G. Haematogenous Staphylococcus aureus meningitis. A 10-year nationwide study of 96 consecutivecases. BMC Infect. Dis. 6, 49 (2006).

7 Chang, F. Y. et al. Staphylococcus aureus bacteremia: recurrence and the impact of antibiotic treatment in a prospective multicenter study. Medicine (Baltimore) $\mathbf{8 2}$, 333-339 (2003).

8 Ciampolini, J. \& Harding, K. G. Pathophysiology of chronic bacterial osteomyelitis. Why do antibiotics fail so often? Postgrad. Med. J. 76, 479-483 (2000).

9 Esen, M. et al. Mechanisms of Staphylococcusaureus induced apoptosis of human endothelial cells. Apoptosis 6, 431-439 (2001).

10 Gresham, H. D. et al. Survival of Staphylococcusaureus inside neutrophils contributes to infection. J.Immunol. 164, 3713-3722 (2000).

11 Van Bambeke, F., Barcia-Macay, M., Lemaire, S. \& Tulkens, P. M. Cellular pharmacodynamics and pharmacokinetics of antibiotics: current views and perspectives. Curr. Opin. Drug Discov. Dev. 9, 218-230 (2006).

12 Barcia-Macay, M., Seral, C., Mingeot-Leclercq, M. P., Tulkens, P. M. \& VanBambeke, F. Pharmacodynamic evaluation of the intracellular activities of antibiotics against Staphylococcusaureus in a model of THP-1 macrophages. Antimicrob. Agents Chemother. 50, 841-851 (2006).

13 Sandberg, A., Hessler, J. H., Skov, R. L., Blom, J. \& Frimodt-Moller, N. Intracellular activity of antibiotics against Staphylococcusaureus in a mouse peritonitis model. Antimicrob. Agents Chemother. 53, 1874-1883 (2009).

14 VanBambeke, F. et al. Cellular pharmacokinetics and pharmacodynamics of the glycopeptides antibiotic oritavancin (LY333328) in a model of J774 mouse macrophages. Antimicrob. Agents Chemother. 48, 2853-2860 (2004).

15 Vande Velde, S., Nguyen, H. A., Van Bambeke, F. \& Tulkens, P. M. Contrasting effects of human THP-1 cell differentiation on levofloxacin and moxifloxacin intracellular accumulation and activity against Staphylococcusaureus and Listeria monocytogenes. J. Antimicrob. Chemother. 62, 518-521 (2008).
16 Keating, G. M. Sitafloxacin in bacterial infections. Drugs 71, 731-744 (2011).

17 Barcia-Macay, M., Seral, C., Mingeot-Leclercq, M- P. \& Tulkens, P. M. Pharmacodynamic evaluation of the intracellular activities of antibiotics against Staphylococcusaureus in a model of THP-1 macrophages. Antimicrob. Agents Chemother. 50, 841-851 (2006).

18 Raschke, W. C., Baird, S., Ralph, P. \& Nakoinz, I. Functional macrophage cell lines transformed by Abelson leukemia virus. Cell 15, 261-267 (1987).

19 Mosmann, T. Rapid colorimetric assay for cellular growth and survival: application to proliferation and cytotoxicity assays. J. Immunol. Methods 65, 55-63 (1983).

20 Zhao, X. \& Drlica, K. Restricting the selection of antibiotic-resistant mutant bacteria: measurement and potential use of the mutant selection window. J. Infect. Dis. 185, 561-565 (2002).

21 Sitafloxacin European patent specification EP1277471B1.

22 Manish Kumar, T., Srikanth, G., Venkateshwar Rao, J. \& Sambasiva Rao, K.R.S. Development and validation of HPLC-UV method for the estimation of Levofloxacin in human plasma. Int. J. Pharm. Pharm. Sci. 3, 247-250 (2011).

23 Lismond, A. \& Tulkens, P. M. Cooperation between prokaryotic (Lde) and eukaryotic (MRP) efflux Transportersin J774 macrophages infected with Listeria monocytogenes: studies with Ciprofloxacin and Moxifloxacin. Antimicrob. Agents Chemother. 52, 30403046 (2008).

24 Tomioka, H., Saito, H., Sato, K. \& Yoneyama, T. Therapeutic efficacy of liposome encapsulated kanamycin against mycobacterium intracellular infection induced in mice. Am. Rev. Respir. Dis. 144, 575-9 (1991).

25 Barcia-Macay, M., Lemaire, S., Mingeot-Leclercq, M. P., Tulkens, P. M. \& Van Bambeke, F. Evaluation of the extracellular and intracellular activities (human THP-1 macrophages) of telavancin versus vancomycin against methicillin-susceptible, methicillin-resistant, vancomycin-intermediate and vancomycin-resistant Staphylococcusaureus. J. Antimicrob. Chemother. 58, 1177-1184 (2006).

26 Zhao, X. \& Drlica, K. Restricting the selection of antibiotic-resistant mutants: a general strategy derived from fluoroquinolone studies. Clin. Infect. Dis. 33(Suppl 3), S147-156 (2001)

27 Baudoux, P. et al. Activity of quinupristin/ dalfopristin against extracellular and intracellular Staphylococcusaureus with various resistance phenotypes. J. Antimicrob. Chemother. 65, 1228-1236 (2010).

28 Lemaire, S. et al. Activities of ceftobiprole and other cephalosporins against extracellular and intracellular (THP-1macrophages and keratinocytes) forms of methicillinsusceptible and methicillin-resistant Staphylococcusaureus. Antimicrob. Agents. Chemother. 53, 2289-2297 (2009).

29 Motulsky, H. J. Analyzing Data with GraphPad Prism (GraphPad Software Inc., San Diego, CA, 2010). 